\title{
Productivity Differences in the Airline Industry: Partial Deregulation versus Short-Run Protection
}

\author{
Pedro L Marin \\ STICERD, London School of Economics and Political Science \\ and Universidad Carlos III de Madrid
}

Discussion Paper

No. El/11

December 1995
The Toyota Centre

Suntory and Toyota International Centres for Economics and Related Disciplines

London School of Economics and Political Science Houghton Street

London WC2A 2AE

Tel.: (020) 79556674

The author would like to thank Monica Gandolfi and Hugh Wills for long and useful discussions. Financial support from the Fundación Ramón Areces and research facilities provided by STICERD are gratefully acknowledged. The usual disclaimer applies. 


\section{Abstract}

The paper specifies and estimates a production function for the airline industry, identifying firms' network characteristics and efficiency as the main determinants of their productivity. The application of this analysis to the European market shows that productivity differences among flag carriers could explain the governments' different views about deregulation at the beginning of the eighties. The introduction of liberal bilateral agreements by some European governments has given their flag carriers incentives to start adjusting their structure in anticipation of future liberalization in the European market while other European flag carriers have delayed this adjustment.

Keywords: Productivity, network characteristics, efficiency, airlines deregulation.

JEL Nos.: D24, L23, L59, L93

(C) by Pedro L Marin. All rights reserved. Short sections of text not to exceed two paragraphs may be quoted without explicit permission provided that full credit, including $(\subset$ notice, is given to the source. 


\section{INTRODUCTION}

This paper analyses the main determinants of productivity in the airline industry, identifying network attributes which lie outside the firms' control, as well as firms' technical and allocative inefficiency. The application of this analysis to the European market allows me to identify airlines' productivity differences at the beginning of the eighties which could have affected the view of the European governments about the timing for introducing deregulatory policies. Additionally, this study aims to evaluate the effects of the alternative policies introduced by the European governments during the eighties.

At the beginning of the eighties, some European countries such as the United Kingdom, the Netherlands, Belgium, Ireland and Germany signed liberal bilateral agreements with the U.S. allowing for free entry, and price and capacity competition on their North-Atlantic routes. Subsequently, between 1984 and 1986 the same countries introduced liberal bilateral agreements between them. During the second half of the eighties, flag carriers from these countries had to face strong competition both in the North Atlantic routes and in many intra-European international routes. 
On the other hand, other European countries, such as Denmark, France, Italy, Portugal and Spain followed a more protective policy, keeping their bilateral agreements highly regulated, and restricting both entry and competition.

Additionally, during the same period the European Commission provided several reports recommending the gradual deregulation of the industry (e.g. European Economic Commission 1984). As a result, the European Council approved a first package of deregulatory measures in 1987 allowing for limited competition in prices and capacities and restricted entry, and so fixing an upper bound for airline regulation within the European Community. These measures were extended in 1990 and 1993. The package of measures introduced in 1993 allows for free entry and price and capacity competition within the European Union.

Therefore, during the second half of the eighties, it is possible to distinguish between two different sets of European countries: those that have liberalised their bilateral agreements with the U.S. and other European countries, and those that keep restrictive agreements with the U.S. and apply the EC legislation to the European international routes. This paper tries to unravel the economic reasons behind these two alternative policies and to measure their effects on firms' 
productivity.

I specify a stochastic production function for the airline industry in which exogenous firms' characteristics are allowed to affect output-factor elasticities, total factor productivity and input combinations ${ }^{1}$ in order to analyze a panel of data for the period 1980-89 that includes European carriers from ten different countries and nine American airlines. Given that domestic and international regulatory agreements limit the freedom of companies to decide the set of routes that they want to supply, the final output can be regarded as exogenous while the inputs are endogenous. Accordingly, I follow the estimation procedure suggested by Kumbhakar (1987) and estimate the first order conditions for the input combinations to obtain a measure of allocative inefficiency. Provided with these estimates I transform and estimate the production function. To test for the robustness of the results, I consider two alternative approaches to measure

${ }^{1}$ Several authors (see Schmidt and Sickles 1984, Sickles 1985 and Cornwell, Schmidt and Sickles 1990, among others) have measured firms' inefficiency taking into account the effect of exogenous characteristics on total factor productivity but not on output-factor elasticities and input combinations. 
technical inefficiency for each firm.

I find that network characteristics affect both total factor productivity and input combinations. I also identify the main differences in efficiency and network characteristics among European flag carriers at the beginning of the eighties and their effect on productivity. I find that these productivity differences could underlay the differences in regulatory policy followed by the European governments. I also find that the introduction of liberalization has given rise to a short run reduction in efficiency that is expected to be followed by long run efficiency improvements. There are two complementary reasons for this short run effect. First, firms may decide to use more productive inputs which require some time before being efficiently utilized. Second, airlines face both the strong opposition from professional associations to reductions in their labour force, and imperfections in the second-hand market for aircraft. This means that the reorganization of their output cannot be immediately followed by adjustments in their input requirements. Accordingly, it seems that companies from countries that introduced liberal bilateral agreements during the eighties had a strong incentive to start implementing adjustment plans and they are expected to start improving their efficiency during the nineties. Airlines from countries with more 
protective regulatory policies seem to have started implementing adjustment plans only recently after the approval of the third EC package of deregulatory measures in 1993. This would lead to a strong asymmetry between these two sets of companies that could be crucial in determining the future market configuration for the European airline industry.

\section{MODEL AND ECONOMETRIC APPROACH}

II(i). On the estimation of production functions

A production function determines the maximum possible output which can be produced from given quantities of a set of inputs, i.e., a limit or frontier to the range of possible observations, such that we can observe points below the production frontier but not above. Accordingly, the amount by which a firm lies below its production frontier can be regarded as a measure of inefficiency. We can distinguish two types of efficiency. Following Forsund, Lovell and Schmidt (1980), let us suppose that a firm has a production plan $\left(Y^{0}, X^{0}\right)$ where the first argument represents the set of outputs and the second the set of inputs. Given production function $f($.), the plan is technically efficient if $Y^{\infty}=f\left(X^{0}\right)$ and technically inefficient if 
$Y^{0}<f\left(X^{0}\right)$. So, one possible measure of technical efficiency is provided by the ratio $0 \leq Y^{0} / f\left(X^{0}\right) \leq 1$. Additionally, assuming $f$ to be differentiable, the plan is allocatively efficient if $f_{i}\left(X^{0}\right) / f_{j}\left(X^{0}\right)=w_{i} / w_{j}$, where $f_{j}$ and $w_{j}$ are the marginal product and the price of input $X_{j}$, correspondingly. Therefore, allocative efficiency implies that inputs are combined in the right proportion given their prices. ${ }^{2}$

The empirical literature on the estimation of production frontiers has as its first benchmark the seminal paper of Farrell (1957) who provided a non-parametric framework for the measurement of both technical and allocative inefficiency based on linear programming techniques. Farrell also proposed a parametric approach that was followed by Aigner and Chu (1968), who specified a production function such as

$$
Y=f(X) \exp (-u)
$$

where the deterministic frontier is $f(x)$ and $u$ is an error term greater or equal than zero that captures the effect of inefficiency relative to the frontier. Note that $u \geq 0$ implies that all the observations lie on or beneath the frontier. The

${ }^{2}$ See Forsund, Lovell and Schmidt (1980) for a more general survey regarding production, cost and profit functions. 
parameters can be "estimated" either by linear or quadratic programming. In this case, the problem is that the "estimators" have no statistical properties. However, the deterministic parametric frontier can be translated into a deterministic statistical frontier by making some assumption about $X$ and $u .^{3}$

A second and more relevant problem arises from more philosophical considerations. The method of estimating a deterministic frontier assumes that all the firms in the sample share a production frontier and any variation in a firm's performance is attributed to a variation in the firm's efficiency relative to the common family frontier. This assumption can be accepted in a theoretical model but is difficult to justify in an empirical analysis. A firm's performance is affected by some factors outside its control (e.g., weather) and some which are under its control (inefficiency). This situation gets reinforced in presence of some statistical noise due either to measurement

${ }^{3}$ Note, however, that the range of the dependent variables depends on the parameters to be estimated which violates one of the regularity conditions necessary to prove the maximum likelihood properties of consistency and asymptotic efficiency. Several authors (see Greene 1980, and Richmond 1974, among others) reconsider this problem and provide solutions. 
error on the dependent variable or to omitted variables which are individually unimportant. ${ }^{4}$

A stochastic production function model may be written as

$$
Y=f(X) \exp (\epsilon)
$$

where $\epsilon$ is an error term defined as $\epsilon=(v-u)$, and $v$ and $u$ are two components independent of each other and defined as follows: $v$ is a symmetric component that measures random variations of the frontier across firms and captures the effects of measurement error, other statistical "noise" and random shocks outside the firm's control, and $u$ is a one-sided component greater or equal than zero that captures the effect of inefficiency relative to the stochastic frontier. Therefore, the stochastic frontier is $f(X) \exp (v)$, and $\exp (-u)=Y / f(X) \exp (v)$ measures technical efficiency relative to the stochastic production frontier. Provided $u \geq 0$, all the observations lie on or beneath the stochastic production frontier. The population average technical inefficiency can be easily calculated and the entire $\epsilon$ is easily estimated for each observation, but the problem is to separate it into its two components, $v$ and $u$.

${ }^{4}$ See Aigner et al. (1977) and Meeusen and van den Broeck (1977). 
Jondrow et al. (1982) suggest a solution to this problem by considering the expected value of $u$ conditional on $\epsilon$, i.e. $\mathrm{E}\left(u_{i} \mid \epsilon_{i}\right)$. A shortcoming of this method is that the researcher must specify the distribution taken by $u$. This problems is mitigated because he can estimate the variance of $u$ and $v$. If he has assumed a wrong distribution for $u$, most of the variation will be picked up by the symmetric component $v$. When the researcher observes this, an alternative distribution should be tried. In particular, Jondrow et al. provide examples when the inefficiency error term, $u$, is assumed to follow the half-normal and the one-sided exponential distributions. Another shortcoming of this approach is that it is designed for cross-section data and cannot be applied to a panel of data. However, Battese and Coelli (1988), provide a solution that conditions the value of $u$ on all the information available in the panel and estimate $\mathrm{E}\left(u_{i} \mid \epsilon_{i I}, \ldots, \epsilon_{i T}\right)$.

Additionally, the availability of panel data allows for an alternative solution. Schmidt and Sickles (1984) consider this case and allow for a different intercept for each firm, interpreting the intercepts as a measure of inefficiency. Also this approach has several shortcomings. First, it cannot measure $u_{i}$ independently of the intercept, but imposes a normalization based on the most efficient firm. Second, the 
introduction of firm fixed effects is equivalent to a transformation of the model in which variables are redefined in terms of differences from each firm's time average values. This implies that all the variables that are time invariant are dropped from the regression, and their effect is included to some extent in the firm fixed effect. If the set of time invariant variables includes relevant and significant variables, the fixed effect will not measure inefficiency but will rather measure the effect of variables exogenous to the firm. In the same paper, Schmidt and Sickles consider some of these problems and propose alternative methods such as GLS and the HausmanTaylor estimation procedure.

One further shortcoming of the previous models is pointed out by Kumbhakar (1987 and 1990) who argues that these estimation procedures may result in inconsistent estimates when the inputs are endogenous. A possible solution to this problem is to follow a cost function approach that assumes that the firms minimise the cost of producing a certain quantity of output, given the input prices. Kumbhakar proposes an alternative procedure which follows the production function approach. In particular, he proposes a two-step estimation procedure. The first step involves the simultaneous estimation of the first order conditions for the input combinations, taking 
as given the level of output and the input prices. The results of this estimation provide a measure of the allocative inefficiency. Substituting the estimates from these equations into the production function, we can obtain a combination of the input requirements that can be expressed as a function of the exogenous level of output. In a second step, the estimation of the transformed production function provides a measure of technical inefficiency. The main advantage of this method with respect to the cost function approach is that it provides a separate measure of allocative and technical inefficiency.

Given that domestic and international regulatory agreements limit the freedom of airlines to decide the set of routes that they want to supply, their final output can be regarded as an exogenous variable while their inputs are endogenous. For this reason, the approach developed by Kumbhakar seems to be quite suitable for the estimation of the production function for the airline industry. In particular, I apply this approach and I use both, Battese and Coelli's (1988) correction on Jondrow et al.'s (1982) method based on the $\mathrm{E}\left(u_{i}\right.$ $\left.\mid \epsilon_{i 1}, \ldots, \epsilon_{i T}\right)$ and Schmidt and Sickles's (1984) fixed effects approach. 
II(ii). Network attributes and their effect on productivity

Kumbhakar's method assumes an homogeneous output but this is not the case for the airline industry where each firm combines a set of outputs (routes) in different proportions. Accordingly, the efficiency of firms that supply different combinations of various outputs cannot be measured unless we include in the production function a set of control variables, $C$, that proxy the main characteristics of the firms' final output mix. It is possible to think about several variables to proxy the characteristics of the firms' network, the most important being the average routes' length or Average Stage Length $(A S L)$, and the concentration of their operations, proxied by the Airport Concentration $(A C) .^{5}$ These two variables measure the distribution of the products supplied as well as the proximity or relatedness among them and are

5 The American literature provides many examples that show the effects of these two variables on firms' costs and profits. For instance, Caves, Christensen and Tretheway (1984) conclude that distance has relevant effects on cost economies, and Evans and Kessides (1993) remark the many effects of airport concentration on firms' conduct and performance. 
expected to affect not only the total factor productivity, but also the output-factor elasticities and the input combinations.

П(iii). Production function for the airline industry

Let us assume a specific form for the airlines' production function $f($.$) including all the characteristics$ mentioned above. For instance, we can assume a CobbDouglas technology for each firm $i$ and period $t$, such as

$$
Y_{i t}=A K_{i t}^{\beta_{1} h_{E}\left(C_{i t}\right)} L_{i t}^{\beta_{2} h_{L}\left(C_{i t}\right)} E_{i t}^{\beta_{3} h_{E}\left(C_{i t}\right)} e^{g t+\epsilon_{i t}}
$$

where $Y$ is the output, $A$ is a constant term, $K, L$ and $E$ represent the capital, labour and fuel inputs, respectively, $h_{j}$ $(C)$, for $j=K, L, E$, are functions of the control variables, $C$, which proxy network attributes, $t$ is a trend dummy variable that measures general technical change, $\beta$ and $g$ are coefficients, and $\epsilon=(v-u)$ is the error term as defined above. It is important to note that in previous studies ${ }^{1}$ the control variables were assumed to affect only the total factor productivity and therefore were included in the production function as a multiplicative term. However, the implicit

1 See Schmidt and Sickles (1984), Sickles (1985) and Cornwell, Schmidt and Sickles (1990), among others. 
assumption that exogenous control variables affect all the inputs in the same proportion has neither theoretical nor empirical justification. For this reason, the specification proposed here includes a different function of the control variables, $h_{j}(C)$, entering the exponent of each input. This implies that the control variables are allowed to affect the output-factor elasticities and, subsequently, the input combinations and the returns to scale.

From the first order conditions for a profit maximizing firm, it is easy to obtain the expressions for the optimal input combinations, which are

$$
\begin{aligned}
& \frac{\beta_{1} h_{K}\left(C_{i t}\right)}{\beta_{3} h_{E}\left(C_{i t}\right)}=\frac{K_{i t} p_{K i t} / Y_{i t}}{E_{i t} p_{E i t} / Y_{i t}} \\
& \frac{\beta_{2} h_{L}\left(C_{i t}\right)}{\beta_{3} h_{E}\left(C_{i t}\right)}=\frac{L_{i t} w_{i t} / Y_{i t}}{E_{i t} p_{E i t} / Y_{i t}}
\end{aligned}
$$

where $p_{K}, w$ and $p_{E}$ are the prices of capital, labour and fuel, respectively, and $h_{j}\left(C_{i}\right)$ can be specified as

$$
h_{j}\left(C_{i t}\right)=A S L_{i t}^{\delta_{1 j}} A C_{i t}^{\delta_{2 j}}
$$

Rewriting the right hand side of equations (4) and (5) as the cost share ratio between capital and fuel, $\left(S_{K} / S_{E}\right)_{i t}$, and labour and fuel, $\left(S_{L} / S_{E}\right)_{i t}$, correspondingly, taking logs 
and substituting for (6), we can rewrite (4) and (5) as follows

$$
\begin{aligned}
\ln \left(S_{K} / S_{E}\right)_{i t} & =\ln \left(\beta_{1} / \beta_{3}\right)+\left(\delta_{1 K}-\delta_{1 E}\right) \ln A S L_{i t} \\
& +\left(\delta_{2 K} \delta_{2 E}\right) \ln A C_{i t}+\eta_{(K, E) i t} \\
\ln \left(S_{L} / S_{E}\right)_{i t} & =\ln \left(\beta_{2} / \beta_{3}\right)+\left(\delta_{I L}-\delta_{I E}\right) \ln A S L_{i t} \\
& +\left(\delta_{2 L}-\delta_{2 E}\right) \ln A C_{i t}+\eta_{(L, E) i t}
\end{aligned}
$$

Following Kumbhakar $(1987,1990)$, I assume $v_{i t}$, $\eta_{(K, E)}$ and $\eta_{(L, E)}$ are independent and identically distributed with zero mean and finite variance, and $v_{i t}$ is independent of $\eta_{(K, E)}$ and $\eta_{(L, E)}{ }^{2}$ Additionally, I allow the $\operatorname{cov}\left(\eta_{(K, E)}, \eta_{(L, E)}\right)$ to be different from zero, which implies that equations (7) and (8) must be estimated simultaneously by a two-step GLS estimation procedure. Finally, I assume error terms of the form $\eta_{i t}=e_{i t}+v_{i}+\mu_{t}$, i.e. there are firm and time specific random components. I recover the firm specific effects, which measure allocative inefficiency, as $\hat{v_{i}}=\Sigma_{t} \hat{\eta}_{i t} / T$. The estimation of these two equations also produces efficient estimates of $\left(\beta_{1} / \beta_{3}\right),\left(\delta_{1 K^{-}}\right.$

${ }^{2}$ According to Schmidt and Lovell (1980) " $u$ and $\eta$ might be expected to be correlated over a long period of time but the relationship between them in any given year is unpredictable as firms follow long term dynamic investment programs and can adjust slowly to changes in market conditions and prices. This means that while we may expect a positive correlation between technical and allocative inefficiency in a dynamic sense, it is not clear that we should expect such a relationship between our static measures of technical and allocative inefficiency". 
$\left.\delta_{1 E}\right),\left(\delta_{2 K} \delta_{2 E}\right),\left(\beta_{2} / \beta_{3}\right),\left(\delta_{1 L}-\delta_{1 E}\right)$, and $\left(\delta_{2 L}-\delta_{2 E}\right)$.

Finally, to estimate equation (3) we define

$$
\begin{aligned}
& z_{i t}=\left(\frac{b_{1}}{b_{3}}\right) A S L_{i t}^{\left(d_{1 K}-d_{1 E}\right)} A C_{i t}^{\left(d_{2 K}-d_{2 E}\right)} \ln K_{i t}+ \\
& \left(\frac{b_{2}}{b_{3}}\right) A S L_{i t}^{\left(d_{1 L}-d_{1 E}\right)} A C_{i t}^{\left(d_{2 L}-d_{2 E}\right)} \ln L_{i t}+\ln E_{i t}
\end{aligned}
$$

where $b_{i}$ and $d_{i j}$ are the estimates of $\beta_{i}$ and $\delta_{i j}$, respectively. ${ }^{3}$ Substituting (6) and (9) in (3), taking logs and solving for $z_{i t}$, we obtain the following expression

$$
z_{i t}=\frac{-\alpha-g t+\ln Y_{i t}-\epsilon_{i t}}{\beta_{3} A S L_{i t}^{8_{1 E}} A C_{i t}^{\delta_{2 E}}}
$$

where $\alpha=\ln A$ and $\epsilon=(v-u)$ as before, where $v$ follows a normal distribution and $u$, that measures technical efficiency is assumed to be positive. We can estimate this equation by Non Linear Least Squares, assuming that $K, L$ and $E$ are endogenous, while $Y$ and the input prices are exogenous. Then I assume that $u$ is distributed as half-exponential and I apply Jondrow et al.'s (1982) approach with the correction

${ }^{3}$ Note that this approach also avoids likely collinearity problems among the inputs. 
introduced by Battese and Coelli (1988) for panel data, to obtain $\mathrm{E}\left(u_{i} \mid \epsilon_{i 1}, \ldots, \epsilon_{i T}\right)$, i.e., the individual estimates for technical inefficiency. I also apply Schmidt and Sickles's (1984) fixed effects method to obtain firm specific intercepts, $\alpha_{i}=\alpha-u_{i}$, that measure technical inefficiency. The estimates provided by these two alternative procedures can be compared to test the robustness of the results.

\section{EMPIRICAL RESULTS}

III(i). Data and Variable Definitions

The sample contains 10 European companies and 9 American carriers for which there were available data. The European firms can be split in two different categories: flag carriers from the countries that introduced liberal bilateral agreements, LBA Flag Carriers, which are AerLingus-Aerlinte, British Airways, KLM, Lufthansa and Sabena, and flag carriers from other European countries, regarded as a control group, Control-Europe, specifically, Air France, Alitalia, Iberia, SAS and Tap AP. Finally, the American carriers constitute a second control group, Control-USA, that includes American, Continental, Delta, Eastern, Northwest, Pan Am, 
TWA, United and USAir.

All the data have been taken from the International Civil Aviation Organization - Digest of Statistics for the period 1980-1989. The measure of output is transferred space, in particular, firm's available seats-Km. ${ }^{9}$ To measure labour inputs, six categories of personnel have been used to construct an index that gives weights to different categories according to their relative real wages. Capital input is measured by the total capacity installed, i.e., the total number of seats available in the firm's fleet. Fuel is measured by the total firm consumption of aircraft fuel and oil. Airport Concentration is defined as one over the firm's cost share devoted to airport services and utilities, and Average Stage Length as the average length of the routes served by each airline weighted by the number of flights on each route. The cost shares of capital, labour and energy are proxied by the actual firms' operating expenses devoted to rental of flight equipment and normal depreciation of flight equipment and ground property and equipment, flight crew salaries and expenses, and aircraft fuel and oil, over total expenses. The data on labour and energy inputs is not

${ }^{9}$ Following Schmidt and Sickles (1984) and Sickles (1985), among others, I assume that any unfilled space is wastage. 
disagreggated for passengers, cargo and mail, so I correct these variables by the share of revenues derived from passenger services. Finally, $t$, the trend variable, is equal to 1 in 1980 and incremented by 1 each year.

III(ii). Estimates for the input combinations and the production function

Table 1 shows the results of estimating the first order conditions for the optimal input combinations represented by equations (7) and (8). These two equations have been simultaneously estimated by a two-step GLS estimator within a two-way Random Effects Model (REM) that assumes an error term of the form $\eta_{i t}=e_{i t}+v_{i}+\mu_{t}$, with firm and time specific components, and allowing for the $\operatorname{cov}\left(\eta_{(K, E) i t}, \eta_{(L, E) i t}\right)$ to be different from zero. The purpose of these two regressions is to measure allocative inefficiency, to obtain estimates for $\beta_{1}$ $\left./ \beta_{3}\right)$ and $\left(\beta_{2} / \beta_{3}\right)$ and to observe whether the control variables, Average Stage Length (ASL) and Airport Concentration $(A C)$, affect the input combinations. The results are the following. First, the coefficient of $\ln A S L$ is not significant in the labourfuel combination equation and is only significant at the $11 \%$ level in the capital-fuel combination equation. This suggests 
Table 1. Input combination equations.

Estimation method: Two-step GLS within a two-way Random Effects Model.

Independent

Dependent variables

variables $\ln \left(S_{K} \underline{S}_{E} L_{i t}\right.$ $\ln \left(S_{L} \underline{S}_{E}\right)_{i t}$

Constant $-5.40$

$-2.96$

$(-2.81)$

$(-1.52)$

$\ln A S L_{\text {it }}$

0.36

0.06

(1.56)

(0.28)

$\ln A C_{i t}$

$-0.70$

$-0.54$

$(-2.78)$

$(-2.18)$

$\operatorname{var}\left(e_{i t}\right)$

0.08

0.08

$\operatorname{var}\left(v_{i}\right)$

0.04

0.06

$\operatorname{var}\left(\mu_{\nu}\right)$

0.03

0.01

$\operatorname{cov}\left(\eta_{i t(K, E)}, \eta_{i t(L, E)}\right)$

0.05

0.05

Number of observations 190

190

Notes:

T-test in parenthesis.

Both equations have been estimated by two-step GLS with error terms of the form $\eta_{i t}=e_{i t}+v_{i}+\mu_{t}$, i.e., with firm and time specific random components, and allowing for $\operatorname{cov}\left(\eta_{i t(K, E)}\right.$, $\left.\eta_{i(\mathcal{L}, E)}\right) \neq 0$. 
that airlines operating on longer routes have higher requirements of capital per unit of both fuel and labour, i.e., on average they are operating larger aircraft. Second, the coefficient of $\ln A C$ is negative and significant in both equations. This means that a larger airport concentration reduces the demand for both capital and labour per unit of fuel, and so per flight, given that we are including the variable $A S L$ in the regression. ${ }^{10}$ The better capital and labour utilization ratios are justified by the greater possibility for sharing these two inputs among different routes when they have more common endpoints.

Provided with this information, we can construct $z$ as defined in (9) and estimate the transformed production function expressed in equation (10) by Non Linear Least Squares. The error term has been decomposed into two terms, $v$ that follows a normal distribution and $u$ that measures technical inefficiency and is assumed to be positive. First, I apply Jondrow et al.'s (1982) approach with the correction

${ }^{10}$ The $A S L$ determines the number of flights to produce a certain output. By including $A S L$ in the regression, we take into account the impact of a different number of departures on the input combinations. 
introduced by Battese and Coelli (1988) for panel data. I assume that $u$ is distributed as half exponential with $f(u)=\theta e^{-}$ $\Theta u$ and obtain $\mathrm{E}\left(u_{i} \mid \epsilon_{i l}, \ldots, \epsilon_{i T}\right)$, i.e., the individual estimates for technical inefficiency. Second, I apply Schmidt and Sickles's (1984) fixed effects method, allowing for a different intercept for each firm which measures technical inefficiency. The results of applying these two alternative approaches are reported in columns (1) and (2) in table 2 , respectively. The results are very robust to changes in the estimation procedure.

The coefficient $g$ represents the annual rate at which the production function shifts as a result of factors not explicitly included in the regression, such as general technical change. The estimate of $g$ is not significant at any level. This suggests that during this period there has not been any significant shift in the production function owing to general technical change. The estimated coefficients for $A S L$ and $A C$ are very significant which means that these two variables affect the elasticity of fuel inputs. Also, the $R^{2}$ and the $F$-test that measure the goodness of the fit are very satisfactory.

Table 3 presents the structural form parameters which are recovered from the estimates given in tables 1 and column (1) in table 2. Provided with these estimates, we can easily construct the average output-factor elasticities for the 
Table 2. Stochastic production frontier. Estimation method: Non-Linear Least Squares. Function to estimate:

$$
z_{i t}=\frac{-\alpha-g t+\ln Y_{i t}-\epsilon_{i t}}{\beta_{3} A S L_{i t}^{\delta_{1 I}} A C_{i t}^{\delta_{2 E}}}
$$

\begin{tabular}{lcc} 
& $(1)$ & $(2)$ \\
\hline$\alpha$ & 8.47 & - \\
$g$ & $(90.01)$ & \\
$\beta_{3}$ & 0.00 & 0.00 \\
& $(0.22)$ & $(0.05)$ \\
$\delta_{I E}$ & 2.78 & 2.43 \\
& $(23.11)$ & $(24.16)$ \\
$\delta_{2 E}$ & -0.08 & -0.07 \\
$R^{2}$ & $(-20.00)$ & $(-20.77)$ \\
$F$ & 0.33 & 0.32 \\
(d.f.) & $(47.78)$ & $(53.46)$ \\
Std. Dev. $(u)$ & 0.99 & 0.99 \\
Std. Dev. $(v)$ & 3431.65 & 2188.84 \\
Number of observations & $(4,186)$ & $(9,180)$ \\
& 0.17 & 0.09 \\
& 0.11 & 0.10 \\
Nos: $t$. & & 190
\end{tabular}

Notes: t-test in parenthesis.

In column (1), the error term, $\epsilon$ has been decomposed in two terms, $v_{i t}$, that follows a normal distribution, and $u_{i}$ distributed as half exponential with $f(u)=\theta e^{-\theta u}$, and technical inefficiency has been calculated as $\mathrm{E}\left(u_{i} \mid \epsilon_{i l}, \ldots, \epsilon_{i T}\right)$ according to Battese and Coelli (1988). In column (2), the terms $u_{i}$ have been added to the intercept, allowing for a different intercept for each firm and interpreting the intercepts as measures of technical inefficiency. 
Table 3. Stochastic production frontier. Estimates for the structural form parameters.
$\begin{array}{ll}\beta_{1} & 0.01\end{array}$
$\delta_{1 L} \quad-0.08$
$\beta_{2} \quad 0.14$
$\delta_{2 L} \quad-0.21$
$\beta_{3} \quad 2.78$
$\delta_{I E} \quad-0.08$
$\delta_{1 K} \quad 0.28$
$\delta_{2 E} \quad 0.33$
$\delta_{2 K} \quad-0.37$

Note:

Structural form parameters derived from results in table 1 and regression (1) in table 2.

three inputs: capital, labour and fuel. These are $0.20,0.14$ and 0.63 , respectively. We also find that a large Average Stage Length increases the elasticity of capital and reduces the elasticity of labour and fuel. This means that when ASL increases, the productivity of one extra unit of capital increases as well while the productivity of one extra unit of either labour or fuel falls. In turn, this result suggests that after an exogenous increase in $A S L$, firms intensify the use of their crew and fuel (e.g. using larger aircraft) substituting these two 
inputs by capital. Additionally, a larger Airport Concentration reduces the output-factor elasticity of capital and labour, and increases the elasticity of fuel. This suggests that airlines can easily share capital and labour inputs among different routes with a common endpoint. Therefore, when airport concentration increases, the productivity of one extra unit of either labour or capital falls. On the other hand, the elasticity of fuel increases with airport concentration. This means that after an exogenous increase in $A C$, firms intensify the use of their fleet and crew (e.g., using smaller aircraft, increasing their frequencies, using the same aircraft and crew to supply more routes, etc.) substituting capital and labour by fuel. I also find that these figures are consistent with constant returns to scale, although I do not impose this restriction in the estimation. In fact, the average returns to scale for the sample are 0.98 which coincides with previous empirical evidence on airlines.

III(iii). Efficiency scores

Table 4 presents the average efficiency scores for the three groups of airlines defined above, i.e., flag carriers from countries that introduced liberal bilateral agreements, flag 
carriers from other European countries and American carriers. To study the evolution of efficiency, when estimating equations (7), (8) and (10) I regard each airline as two different firms, one for each half of the sample period. Note that an efficient company has a score of 1 , with decreasing scores implying lower levels of efficiency. The table includes two measures of technical efficiency for each firm and period, based on regressions (1) and (2), respectively. As mentioned above, in regression (2) it is impossible to distinguish the inefficiency component from the intercept. Most authors impose a normalization setting the efficiency score of the most efficient firms equal to one. In this case, I set it equal to 0.83 , the measure provided by regression (1). This makes the two sets of figures easily comparable. We find that differences between the two sets of figures are very small and they both provide the same ranking for the six subsamples of firms.

The situation during the first half of the eighties when the European governments decided the type of policy they wanted to implement in the next years was the following. In average terms, the Control-Europe group is the most inefficient while there were no differences between the other two sets of companies. It is rather unexpected to observe that there are no relevant differences between American and some 
Table 4. Efficiency scores. ${ }^{1}$
Alloc. $(\mathrm{K}, \mathrm{E})^{2}$
Alloc.(L,E)

1980-84 1985-89

$1980-84 \quad 1985-89$

$\begin{array}{lllll}\text { LBA Flag Carriers }^{3} & 0.62 & 0.57 & 0.94 & 0.91\end{array}$

$\begin{array}{lllll}\text { Control-Europe } & 0.71 & 0.43 & 0.80 & 0.80\end{array}$

Control-USA

0.63

0.60

0.91

0.92

Technical

Regression (1)

Regression (2)

$\begin{array}{llll}1980-84 & 1985-89 & 1980-84 & 1985-89\end{array}$

$\begin{array}{lllll}\text { LBA Flag Carriers } & 0.76 & 0.66 & 0.70 & 0.66\end{array}$

$\begin{array}{lllll}\text { Control-Europe } & 0.64 & 0.69 & 0.66 & 0.68\end{array}$

$\begin{array}{lllll}\text { Control-USA } & 0.77 & 0.83 & 0.78 & 0.83\end{array}$

\section{Average $^{4}$}

1980-84 1985-89

LBA Flag Carriers $\quad 0.77 \quad 0.71$

$\begin{array}{lll}\text { Control-Europe } & 0.72 & 0.64\end{array}$

$\begin{array}{lll}\text { Control-USA } & 0.77 & 0.78\end{array}$

Notes: ${ }^{1}$ An efficient firm has a score of 1 , with decreasing scores implying lower levels of efficiency.

${ }^{2}$ Allocative inefficiency from absolute values.

${ }^{3}$ For a definition of the firms included in each group, see section III(i).

${ }^{4}$ Average values have been calculated using technical inefficiency according to regression (1). 
European carriers, since previous papers (see, for instance, Encaoua 1991) have suggested higher efficiency scores for the American carriers - an explanation for this result is given below. Differences become more relevant when looking at specific types of inefficiency. American carriers and LBA flag carriers are better at combining labour with fuel inputs while the other European flag carriers are better at combining capital with fuel. Low capital-fuel efficiency scores are expected for firms facing long-term dynamic investment programs. This can be the case for American airlines, competing in a liberalized domestic market since 1978, and also of some LBA flag carriers, given that at the beginning of the eighties their governments introduced liberal agreements with the U.S. affecting the main North-Atlantic routes. Additionally, the attitude of some governments such as the British and the Dutch governments, which were very committed to the liberalization of their markets, could have given incentives to their flag carriers to start long term dynamic investment processes to renew their fleet. Differences in technical efficiency are also significant, with American carriers ahead in the efficiency ranking followed by LBA and other European flag carriers. It is clear that during the first half of the eighties the companies in the LBA group were more efficient than the Control-Europe 
carriers. However, it is difficult to assess if these differences warrant the different views of European governments on deregulation.

Table 4 also provides information about the evolution of these three sets of firms during the eighties. With respect to allocative efficiency the results are the following. The changes in the Control-Europe group are very small. We only observe a relevant fall in capital-fuel allocative efficiency. As before a likely explanation for this change is the introduction by these companies of dynamic investment programs as a response to the first deregulatory measures introduced by the European Council in 1987 and the announcement of further liberalization at the beginning of the nineties. However, given the limited scope of these measures, firms did not find incentives to reorganise their labour demand. On the other hand, the situation of the US carriers is very stable. The deregulation of the U.S. domestic market had taken place as early as 1978 and during the period 1980-84 we observe its short run effects. Thus, during the second half of the eighties we find quite stable allocative efficiency scores. Finally, we find that allocative efficiency scores fall for the LBA group. It is likely that this general negative effect is a short run effect provoked by the introduction of the liberal 
agreements. The introduction of competition and the possibility of partially restructuring the companies' network implies important adjustments in capital and labour input demands that cannot be made in a short period. This would explain the reduction in allocative efficiency.

Figure 1 provides further information about the evolution of technical efficiency. This figure has been constructed using the group average error term, $\epsilon$. Assuming that the component $v$ is the same for all the firms in every period, i.e., it is an exogenous international demand shock, it is possible to compare the evolution of efficiency among the three groups by dividing each group mean value by the time mean. Both figure 1 and table 4 suggest the following evolution for the American carriers. During the first half of the eighties, we observe efficiency scores below the American sample average, followed by efficiency improvements during the second half of the eighties. We could interpret the low efficiency scores in 198084 as a short run effect from the US domestic deregulation introduced in 1978. This would explain why we do not observe differences between American and LBA carriers during the first half of the eighties. Accordingly, the set of LBA carriers start reducing their efficiency after the introduction of the first liberal agreements with the US around 1982 and face even 


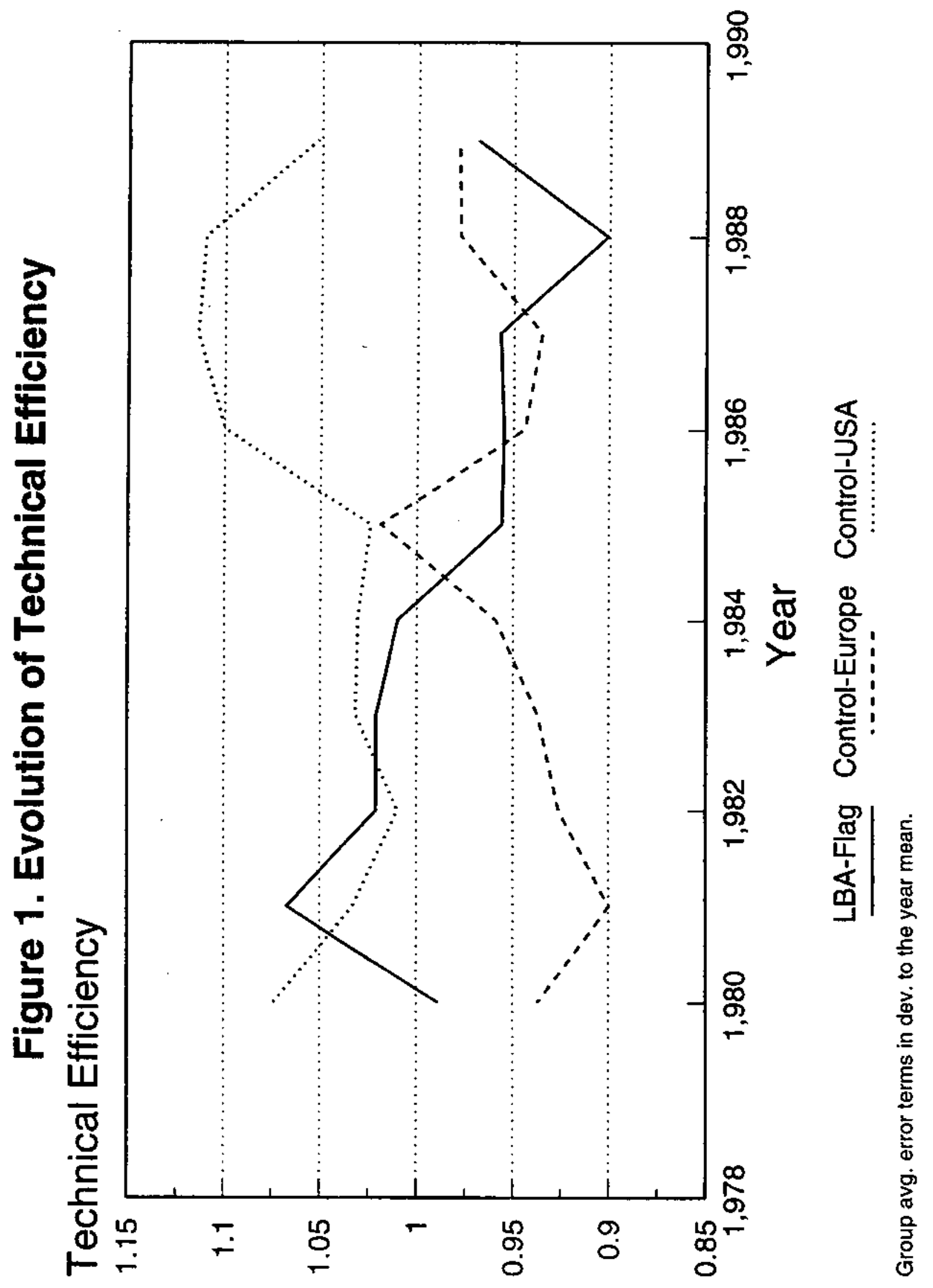


stronger reductions in efficiency after the introduction of the European liberal bilateral agreements around 1984. Finally, flag carriers from other European countries follow a quite stable path throughout the period, with efficiency scores below the average in all but one single year - a value of one means that the group average is equal to the sample average in this period. As a result of all these changes the difference between American and European carriers becomes larger with the American carriers becoming the most efficient, followed by LB Flag carriers and other European flag carriers, which is consistent with previous studies.

Figure 1 and table 4 suggest that the introduction of liberalization has given rise to short run reductions in efficiency that are expected to be followed by long run efficiency improvements. It is possible to think to two complementary reasons for this short run effect. First, airlines face more competition in the market as a result of new legislation, and need to adjust their inputs. Given that some inputs, such as capital and labour need to follow adjustment and learning processes before being fully productive, input requirements can increase without leading to an output expansion in the short run and, in turn, efficiency falls. Second, under more liberal legislation, airlines have the 
opportunity of reorganizing their output, reducing their service in, or exiting from, some routes. This reduction in output cannot always be followed by an instantaneous reduction in input requirements. In fact, this is the case for labour, owing to the power of professional associations, and capital, due to imperfections in the second-hand market for aircraft. The strong opposition that most European airlines face when they try to reduce their labour force is a clear example of this problem. These results suggest that when the third package of measures was introduced by the European Council in 1993, there were large differences in efficiency among the European flag carriers, partly due to the different deregulatory policies followed by their governments during the eighties. On the one hand, flag carriers from countries that introduced liberal bilateral agreements during the eighties were more efficient and had been going through an adjustment process during the second half of the eighties to adapt their crew and fleet to new competition. These companies are expected to experience efficiency improvements during the nineties. On the other hand, flag carriers from other European countries were less efficient, mainly for allocative reasons. After the deregulatory measures introduced by the European Council in 1993, these companies still had to implement important adjustment plans 
that would further reduce their efficiency in the short run.

III(iv). Determinants of productivity: network characteristics and efficiency differences.

Efficiency is not the only determinant of productivity. As tables 1 and 2 show, exogenous network characteristics also play an important role in determining firms' productivity. To compare the effect of network characteristics and efficiency differences on total factor productivity I measure the difference in output among the three sets of firms in both periods, 1980-84 and 1985-89. To obtain these results I use the fitted production function, based on the structural form parameters derived from table 1 and regression (2) in table 2. Table 5 presents the total difference in output between any two sets of firms in the sample. Differences in output can be explained by three factors: differences in input requirements, in efficiency and in network characteristics. In an industry with efficient firms and homogeneous networks, differences in input requirements would explain the total difference in output, i.e., firms would differ only in size.

The top panel in table 5 shows differences between European and American carriers. The results are the following. 
Table 5. Determinants of the differences in output explained by fitted production function.

A. Differences with respect to Control-USA.

LBA Flag Carriers Control-Europe $1980-84 \quad 1985-89 \quad 1980-84 \quad 1985-89$

$\begin{array}{lllll}\text { Total Difference } \quad 58.46 \% & 66.77 \% & 64.53 \% & 72.85 \%\end{array}$

Determinants (as a percentage of the total difference):

Network characteristics:

$\begin{array}{lrrrr}A S L & 0.59 \% & -0.11 \% & 1.96 \% & 0.81 \% \\ A C & 1.91 \% & 0.17 \% & -0.54 \% & -0.38 \%\end{array}$

Efficiency differences $7.47 \% \quad 12.87 \% \quad 9.53 \% \quad 8.25 \%$ $\begin{array}{lllll}\text { Input differences } \quad 90.03 \% & 87.07 \% & 89.05 \% & 91.32 \%\end{array}$

B. Differences with respect to LBA Flag Carriers

Control-Europe

1980-84 1985-89

Total Difference $\quad 14.62 \% \quad 18.31 \%$

Determinants (as a percentage of the total difference):

Network characteristics:

$\begin{array}{lrr}A S L & 14.08 \% & 12.31 \% \\ A C & -20.01 \% & -8.65 \% \\ \text { ciency diff. } & 36.13 \% & -13.16 \% \\ \text { tifferences } & 69.80 \% & 109.50 \%\end{array}$

Note:

These figures are derived from the estimates presented in table 1 and regression (2) in table 2. 
On average during the eighties, European airlines are smaller than American carriers and the difference in size increases over the period. The difference in input requirements do not fully explain the difference in output showing that European airlines are less productive than American carriers. On average, technical efficiency explains less than the $10 \%$ of this difference. As we have seen before, the technical efficiency of LBA flag carriers has fallen drastically during the period in relation to the American carriers. Other European firms remain quite stable. $A S L$ explains a very small share of the difference in output between LBA and American carriers and its effect reduces over the sample period. On the other hand, $A S L$ explains almost $2 \%$ of the difference in output between other European and American carriers during the first half of the eighties but less than $1 \%$ during the second half of the decade. Finally, $A C$ explains almost $2 \%$ for LBA flag carriers in 1980 84, but only $0.2 \%$ in $1985-89$. Other European firms have a very small advantage over American carriers in terms of $A C$, which has also been falling during the sample period. In general, these figures suggest that, during the eighties, airlines are converging in their average network characteristics, but differences in technical efficiency persist.

The bottom panel in table 5 shows differences 
between LBA flag carriers and other European flag carriers. The figures show that LBA flag carriers are larger than Control-Europe airlines and the difference in size has been increasing during the sample period. In 1980-84, the difference in input requirements does not justify the difference in output. This means that during this period Control-Europe airlines were less productive than LBA flag carriers which could justify the different view of their governments about deregulation. In particular, LBA carriers are more efficient than other European flag carriers and enjoy some advantages in terms of $A S L$. However, they also suffer from a large disadvantage in terms of $A C$. In the period 1985-89, differences in network characteristics are smaller, mainly in terms of $A C$, and differences in technical efficiency have experienced an important change. Now LBA carriers are less efficient that other European flag carriers on average. As mentioned above, this seems to result from the short run effects of the introduction of the liberal bilateral agreements. As a result, during the period 1985-89, Control-Europe airlines are more productive than LBA flag carriers. Nevertheless, according to the previous analysis we expect this situation to change at the beginning of the nineties when LBA carriers are expected to start improving their technical efficiency and other European 
carriers are expected to start adjusting their input combinations and network structure following the introduction of the third package of EC deregulatory measures.

\section{CONCLUDING REMARKS}

This paper shows that during the first half of the eighties the flag carriers from the countries that signed liberal bilateral agreements were more productive than other European flag carriers, due to their higher efficiency. Therefore, differences among flag carriers could have affected the different view of the European governments about the timing of the deregulatory process. It also shows that the introduction of deregulatory measures is followed by short run reductions in efficiency and long run efficiency improvements. The choice by some European countries of partial deregulation has led to more competition in some of the main routes where their flag carriers were operating. This competition was strong enough to encourage the airlines to start implementing tough adjustment processes to improve their competitive position in the long run. However, this adjustment had the effect of reducing their efficiency in the short run, but it has taken place while these firms were still enjoying protection in both their 
domestic markets and many international European routes regulated by restrictive bilateral agreements.

On the contrary, the choice of maintaining more protective policies by other European governments has not given the firms enough incentives to start adjusting their organizational structure to cope better with the expected future liberalization of the European market. In the nineties, flag carriers from these European countries find themselves in a difficult situation since they are less efficient than some of their rivals and still have to follow a long term dynamic adjustment process that is going to further reduce their efficiency in the short run. This adjustment will have to take place while facing much stronger competition both in the international European routes and in their domestic markets. In this sense, the decision of some countries of implementing partial deregulation at the beginning of the eighties has given an important advantage to their flag carriers, which may prove crucial in determining the final market configuration in the European airline industry.

Additionally, the estimation of a production function for the airline industry has shown that network attributes have an important effect on firms' productivity. Most of these factors are outside the firms' control and, therefore, cannot be regarded as inefficiency. The results also show that network 
attributes have different effects on output-factor elasticities and input combinations and this must be taken into account when specifying the production function. 


\section{REFERENCES}

Aigner, D., Lovell, C.A.K. and P. Schmidt, 1977, Formulation and Estimation of Stochastic Frontier Production Function Models, Journal of Econometrics 6, 21-37.

Aigner, D. and S. Chu, 1968, On Estimating the Industry Production Function, American Economic Review 53, 826-839.

Battese, G. and T. Coelli, 1988, Prediction of Firm-Level Technical Efficiencies with a Generalized Frontier Production Function and Panel Data, Journal of Econometrics 19, 233238.

Caves, D.W., Christensen, L.R. and M.W. Tretheway, 1984, Economies of Density versus Economies of Scale: Why Trunk and Local Service Airline Costs Differ, Rand Journal of Economics 15, Winter, 471-489.

Cornwell, C., Schmidt, P. and R.C. Sickles, 1990, Production Frontiers with Cross-Sectional and Time-Series Variations in Efficiency Levels, Journal of Econometrics 46, 185-220.

Encaoua, D., 1991, Liberalizing European Airlines. Cost and Factor Productivity Evidence, International Journal of Industrial Organization 9, 109-140.

European Economic Commission, 1984. Civil Aviation 
Memorandum No.2. Progress towards the development of a community air transport policy (COM (84) 72 - Final, EC, Brussels).

Evans. W.N. and I. Kessides, 1993, Structure, Conduct, and Performance in the Deregulated Airline Industry, Southern Economic Journal, 450-67.

Farrell, M.J., 1957, The Measurement of Productive Efficiency, Journal of the Royal Statistical Society A120, 253281.

Forsund, F.R., Lovell, C.A.K. and P. Schmidt, 1980, A Survey of Frontier Production Functions and of their Relationship to Efficiency Measurement, Journal of Econometrics 13, 5-25.

Greene, W.H., 1980, On the Estimation of a Flexible Frontier Production Model, Journal of Econometrics 13, 101115.

Jondrow, J., Lovell, C.A.K., Masterov, I.S. and P. Schmidt, 1982, On the Estimation of Technical Inefficiency in the Stochastic Frontier Production Function Model, Journal of Econometrics 19, 233-238.

Kumbhakar, S.C., 1987, Production Frontiers and Panel Data: an Application to U.S. Class 1 Railroads, Journal of Business and Economic Statistics, vol. 5, no. 2, April, 249- 
255.

Kumbhakar, S.C., 1990, Production Frontiers, Panel Data, and Time-Varying Technical Inefficiency, Journal of Econometrics 46, 201-211.

Meeusen W. and J. van den Broeck, 1977, Efficiency Estimation from Cobb-Douglas Production Functions with Composed Error, International Economic Review 18, June, 435-444.

Richmond, J., 1974, Estimating the Efficiency of Production, International Economic Review, vol. 15, no. 2, June, 515-521.

Schmidt, P. and C.A.K. Lovell, 1980, Estimating Stochastic Production and Cost Frontiers when Technical and Allocative Inefficiency are Correlated, Journal of Econometrics 13, 83-100.

Schmidt, P. and R.C. Sickles, 1984, Production Frontiers and Panel Data, Journal of Business and Economic Statistics, vol. 2 , no. 4, October, 367-374.

Sickles, R.C., 1985, A Nonlinear Multivariate Error Components Analysis of Technology and Specific Factor Productivity Growth with an Application to the U.S. Airlines, Journal of Econometrics 27, 61-78.

Sickles, R.C., Good, D. and R.L. Johnson, 1986, 
Allocative Distortions and the Regulatory Transition of the U.S. Airline Industry, Journal of Econometrics 33, 143-163. 